\title{
Origin of Ligand-Driven Selectivity in Alkyne Semihydrogenation over Silica-Supported Copper Nanoparticles
}

Nicolas Kaeffer, ${ }^{a, \hbar}$ Kim Larmier, ${ }^{a, b, *}$ Alexey Fedorov, ${ }^{a, c}$ Christophe Copéret ${ }^{a, *}$

a) ETH Zürich, Department of Chemistry and Applied Biosciences, Vladimir-Prelog-Weg 1-5, CH-8093, Zürich, Switzerland.

b) Current address: IFP Energies nouvelles, Rond-Point de l'échangeur de Solaize, BP3, 69360 Solaize, France.

c) Current address: ETH Zürich, Department of Mechanical and Process Engineering, Leonhardstrasse 21, CH-8092 Zürich, Switzerland.

Alkyne Semihydrogenation; Copper Nanoparticles; Ligand-Assisted Catalysis; Selectivity; Adsorption Effects 


\section{ABSTRACT}

20 Copper nanoparticles supported on silica are an earth-abundant catalyst efficient for alkyne hydrogenation, yielding high selectivity towards (Z)-olefin when organic ligands are added. Here, we investigate the origin of this selectivity by studying kinetics of the hydrogenation of the prototypical 1-phenyl-1-propyne substrate. Hydrogenation occurs stepwise on the unmodified catalyst, with first the formation of the $(Z)$-alkene followed by overhydrogenation to the alkane. Adsorption isotherms and kinetic modelling evidence that these consecutive processes result from the high adsorption constant of the alkyne onto $\mathrm{Cu}$ compared to that of the alkene, as confirmed by DFT calculations. Ligands (tricyclohexylphosphine and an NHC) display adsorption constants similar to that of the alkyne, which allows for its hydrogenation but leads to the displacement of the generated alkene from the catalyst, thereby preventing the overhydrogenation. Our findings thus rationalize the observed selectivity and guide the choice of ligands for selective semihydrogenation to $(Z)$-olefins with $\mathrm{Cu}$-based catalysts. 


\section{INTRODUCTION}

Alkyne semihydrogenation is a key process for the selective synthesis of ( $Z$ )-alkenes, used both in academia $^{[1]}$ and in industry, especially for the manufacturing of fine chemicals. ${ }^{[2]}$ Semihydrogenation catalysts are typically based on $\mathrm{Pd}$ and the Lindlar catalyst $\left(\mathrm{Pd} / \mathrm{CaCO}_{3} / \mathrm{Pb}(\mathrm{OAc})_{2} /\right.$ quinoline $)$ is still widely used, ${ }^{[3,4]}$ despite the high price of $\mathrm{Pd}$ and the toxicity of lead additive present in this catalyst. These caveats have motivated research to identify cheaper and more environmentally friendly catalysts for the selective alkyne semihydrogenation. ${ }^{[5-8]}$ Whether they are homogeneous or heterogeneous, a key requirement for any alternative semihydrogenation catalyst is its ability to retain high selectivity towards $(Z)$ alkenes at full alkyne conversion. ${ }^{[9]} \mathrm{Cu}$ catalysts, either in the form of molecular complexes ${ }^{[10-14]}$ or supported materials, ${ }^{[15-18]}$ are active for the selective alkyne semihydrogenation with molecular hydrogen as the reducing agent. ${ }^{[12-14,16-18]}$ In particular, our group has recently reported that small (ca. $2 \mathrm{~nm}$ ) $\mathrm{Cu}$ nanoparticles dispersed on partially dehydroxylated silica support $\left(\mathbf{C u} / \mathrm{SiO}_{2}\right)$ are efficient catalysts for hydrogenation of a broad range or alkynes under relatively mild conditions $\left(20-50\right.$ bar $\left.\mathrm{H}_{2}, 40-60{ }^{\circ} \mathrm{C}\right) \cdot{ }^{[17,}{ }^{18]}$ However, overhydrogenation to the corresponding alkanes, which decreases the selectivity towards desired $(Z)$-alkenes, is observed unless ligands such as phosphines, an N-heterocyclic carbene (IMes) or amines are added to the reaction mixtures. ${ }^{[17]}$ In the absence of a ligand, overhydrogenation of the prototypical alkyne 1phenyl-1-propyne (S) to the alkane (1-phenylpropane, $\mathbf{S}_{4 \mathbf{H}}$ ) occurs at very fast rates when high alkyne conversions are reached. In sharp contrast, when tricyclohexylphosphine $\left(\mathrm{PCy}_{3}\right)$ is added to the catalytic mixture $\left(\mathrm{PCy}_{3} / \mathbf{S}\right.$ molar ratio of 1:50), overhydrogenation is strongly inhibited, resulting in a very high selectivity towards the $(Z)$-olefin $(Z)-\mathbf{S}_{2 \mathbf{H}}(94 \%$ selectivity) at full conversion. The dramatic difference of kinetic profiles sparked our interest in understanding which factors govern the kinetics and what is the origin of this remarkable change in selectivity in this catalytic system.

Here, we carry out an in-depth kinetic investigation of 1-phenyl-1-propyne semihydrogenation on $\mathbf{C u} / \mathrm{SiO}_{2}$ in the absence or in the presence of ligands ( $\mathbf{L}=\mathrm{PCy}_{3}$ and IMes) focusing on parameters that control the selectivity of this reaction. Adsorption isotherms, $\mathrm{H}_{2}$ consumption profiles, kinetic modelling and DFT calculations allow identifying the favored competitive adsorption of $\mathbf{L}$ versus the semihydrogenation product as the main factor responsible for the 
near-perfect chemoselectivity to $(Z)-\mathbf{S}_{2 \mathrm{H}}$. Our findings demonstrate that selecting a ligand based on its adsorption coefficient is a viable and simple strategy to reach high selectivity for alkyne semihydrogenation over $\mathrm{Cu}$ catalysts while maintaining intrinsic activity of the unmodified catalyst.

\section{EXPERIMENTAL PART}

\section{General methods}

Unless otherwise noted, all experiments were conducted with dry, oxygen-free solvents using standard Schlenk techniques or in $\mathrm{N}_{2}$ or Ar-filled gloveboxes and reagents were obtained from commercial suppliers and used as received. Toluene and pentane were purified by passage through double solvent purification alumina columns (MBraun). 1-Phenyl-1-propyne, (Z)-1phenyl-1-propene, (E)-phenyl-1-propene, 1-phenylpropane and 1-phenyl-1-hexyne were degassed by three freeze-pump-thaw cycles and then high-vacuum transferred in Rotaflo-type Schlenk vessels, stored in a glove-box over $3 \AA$ molecular sieves and passed over activated alumina just before use. Tricyclohexylphosphine was purchased from Aldrich and recrystallized from pentane. IMes (1,3-bis(2,4,6-trimethylphenyl)imidazol-2-ylidene) was synthetized by a procedure adapted from the literature. ${ }^{[19]} \mathbf{C u} / \mathbf{S i O}_{2}$ material was prepared according to a reported procedure. ${ }^{[17]}$ Gas chromatography (GC) analysis were performed on Shimadzu-QP 2010 Ultra equipped with FID and MS detectors using an HP-5 column, $\mathrm{N}_{2}$ as a carrier gas $\left(30 \mathrm{~mL} \cdot \mathrm{min}^{-1}\right)$ and the following temperature program: a ramp of $15^{\circ} \mathrm{C} \cdot \mathrm{min}^{-1}$ from $70{ }^{\circ} \mathrm{C}$ to $260^{\circ} \mathrm{C}$, then $260^{\circ} \mathrm{C}$ for $15 \mathrm{~min}$.

\section{Adsorption isotherms}

Stock solutions of the substrates in toluene (typically $100 \mathrm{mM}$ ) were prepared using volumetric flasks. A $10 \mathrm{mM}$ solution of tridecane in toluene was prepared as a GC standard solution. Further manipulations were performed using a computer-controlled liquid handling robot (Lissy 4G150 from Zinsser Analytic) operated inside a glovebox. The stock solutions of substrates were diluted with toluene to prepare 50,10 and $5 \mathrm{mM}$ toluene solutions. Fumed-glass vials containing known amounts of $\mathbf{C u} / \mathrm{SiO}_{2}$ material (typically $100 \mathrm{mg}$ per vial) were filled with $2 \mathrm{~mL}$ toluene. In a typical experiment, glass vials were then placed in the orbital-shaking rack of the robot, covered 
with a polymer-padded metal lid, warmed up to $40{ }^{\circ} \mathrm{C}$ and agitated at $400 \mathrm{rpm}$ for $15 \mathrm{~min}$. After this step, $200 \mu \mathrm{L}$ aliquots were sampled from the adsorption mixtures into GC vials and further diluted with $200 \mu \mathrm{L}$ of a standard solution of tridecane. The vials were crimp-capped and taken out of the glovebox for GC analysis. Additional $200 \mu \mathrm{L}$ aliquots of $100,50,10$, or $5 \mathrm{mM}$ solutions of respective substrates were then added to $\mathbf{C u} / \mathbf{S i O}_{2}$ adsorption mixtures. The vials in the rack were sealed again with the lid, the rack agitated at $40{ }^{\circ} \mathrm{C}$ at $400 \mathrm{rpm}$ for an additional 15 min period and the sampling-addition-stirring sequence was repeated 15 times to obtain the adsorption isotherms. Sampled aliquots were analyzed by GC and areas of GC peaks were calculated using a batch processing mode. Areas of GC peaks were normalized against the area of the tridecane peak. GC calibration curves were obtained by analyzing solutions of known concentrations of substrates and the tridecane standard. A Fortran 95 code was used to automatize the construction of adsorption isotherms from the GC peak area data.

\section{Kinetic studies}

Kinetic studies were performed on an 8-parallel reactor autoclave (Endeavour, Biotage) operated inside a glove box. ${ }^{[20]}$ The $\mathrm{H}_{2}$ feed was passed through activated $\mathrm{Cu} / \mathrm{Al}_{2} \mathrm{O}_{3}$ sorbent (BASF) and activated 4-Å molecular sieves. Stock solutions of substrates in toluene (typically 1

$110 \mathrm{M}$ ) and of ligands in toluene (typically 10 and $100 \mathrm{mM}$ ) were prepared using volumetric flasks. In a typical experiment, $20.0 \mathrm{mg}$ of $\mathbf{C u} / \mathbf{S i O}_{2}$ material were charged in reactor vessels and appropriate volumes of a ligand solution introduced with a micropipette. The reactors were then placed in the 8-port autoclave and purged 5 times with $\mathrm{H}_{2}$ (25 bar; throughout the manuscript the pressure is referenced to atmospheric pressure). The reaction media were stirred at $500 \mathrm{rpm}$ and set to 10 bar $\mathrm{H}_{2}$ pressure at $40^{\circ} \mathrm{C}$. Once both parameters equilibrated, a substrate solution (typically $1200 \mu \mathrm{L}$ of a $1 \mathrm{M}$ solution) at $40{ }^{\circ} \mathrm{C}$ was added through a gas-tight injector port that was further washed by a $600 \mu \mathrm{L}$ of toluene preheated to $40{ }^{\circ} \mathrm{C}$. Reactions were performed under quasi-isobaric conditions, with pressure rising to 11 bar upon injection of the substrate solution and stabilizing at 10 bar due to $\mathrm{H}_{2}$ consumption and automatic refilling of $\mathrm{H}_{2}$ to the set value. $\mathrm{H}_{2}$ consumption data were recorded using the Endeavour Advanced software. At the end of the catalytic run, $200 \mu \mathrm{L}$ aliquots were sampled from all reactors into GC vials, $200 \mu \mathrm{L}$ of a standard solution of tridecane were added into each vial. Reaction mixtures were analyzed by GC and areas of GC peaks were acquired using a batch processing mode. Areas of GC peaks were 
normalized against the area of the tridecane peak. Final concentrations in substrates were determined from normalized areas using a GC calibration using the same response factors for all substrates. $\mathrm{H}_{2}$ consumption profiles were normalized using final concentrations in substrates. Selectivities are given assuming a carbon balance of $100 \%$, according to the previous report $(>95 \%){ }^{[17]}$

\section{Gas adsorption}

$\mathrm{H}_{2}$ and $\mathrm{CO}$ chemisorption were performed using a Belsorp-Max (BEL Japan, Inc.) instrument. Approximately $100 \mathrm{mg}$ of each sample were loaded into cells in an Ar-filled glovebox. $\mathrm{H}_{2}$ adsorption experiments were performed at 5, 25,37, 50 and $70{ }^{\circ} \mathrm{C}$ under isothermal conditions using a bath regulated by a Julabo GF40 circulating thermostat. CO adsorption experiments were

135 performed at $25^{\circ} \mathrm{C}$. Samples were reactivated at $300^{\circ} \mathrm{C}$ under vacuum prior to each measurement.

\section{Kinetic modelling}

Kinetic modelling was performed using the Langmuir-Hinshelwood-like formalism described below. The set of non-linear differential equations determining the evolution of the concentrations of species in solution was numerically solved using a Runge-Kutta 4 algorithm, which was verified for convergence with time steps of $5 \cdot 10^{-3} \mathrm{~h}$ (for a total simulated duration of $24 \mathrm{~h}$ ). The simulated curves were fitted to the experimental data by relaxing one or several parameters of the rate equations in order to minimize the root mean square error defined by

145 Equation 1:

\section{Equation 1}

$$
R M S E=\sqrt{\frac{1}{n} \sum_{i=1}^{n}\left(y_{t_{n}, \text { calc }}-y_{t_{n}, \text { exp }}\right)^{2}}
$$

where $y_{t_{n}, \exp }$ and $y_{t_{n}, \text { calc }}$ are respectively the experimental and calculated values at time $t_{n}$. In practice, $y$ is the consumption of $\mathrm{H}_{2}$ monitored by the Endeavour reactor and normalized using GC measurements. The whole procedure was implemented in a home-made Fortran 95 code. Root mean square errors (RMSE) are reported in the text for $n=630$ for all simulations. 


\section{Ab initio calculations}

Periodic ab initio calculations were performed in the frame of the Density Functional Theory using the plane-wave pseudopotential method implemented in VASP (Vienna Ab initio Simulation Package). ${ }^{[21,}{ }^{22]}$ We used the generalized gradient approximation exchangecorrelation functional of Perdew, Burke and Ernzerhof $(\mathrm{PBE})^{[23]}$ with corrections of dispersion forces from the Grimme approach $(\mathrm{DFT}+\mathrm{D} 3) .{ }^{[24]}$ The valence electrons wave functions are projected on a set of plane-waves with a cutoff energy of $400 \mathrm{eV}$. Convergence criterion for the electronic self-consistent field relaxation was set to $10^{-5} \mathrm{eV}$. Geometry optimizations were performed using a conjugate-gradient algorithm with a convergence criterion on forces exerted on atoms set to $0.01 \mathrm{eV} \cdot \AA^{-1}$. We used surface models for the (100) and (111) surface terminations of $f c c$ copper containing 4 atomic layers of $\mathrm{Cu}$ surmounted by $23 \AA$ of vacuum. The simulation boxes consist in $6 \times 6$ repetition of the elementary cells of each surface, respectively $15.0 \times 15.0 \times 28.0$ and $15.4 \times 15.4 \times 28.0 \AA^{3}$ large $(144 \mathrm{Cu}$ atoms $)$. Only the two upper layers of the copper surface slabs are allowed to relax during geometry optimizations. The gas-phase energies of the adsorbates are calculated by placing the molecules in $30 \AA$-large cubic simulation boxes to perform geometry optimization at the same level of theory. Adsorption energies of an adsorbate $\mathrm{A}_{(\mathrm{g})}$ reported as $\Delta_{\mathrm{ads}} \mathrm{E}$ correspond to the following adsorption reaction:

\section{Equation 2}

$$
\mathrm{A}_{(\mathrm{g})}+\{\text { Surface }\}=\{\mathrm{A}-\text { Surface }\}
$$

The energy of deformation of the surface or the adsorbates associated with the adsorption processes are determined by calculating single-point energy on the geometry of either the surface or the adsorbate extracted from the $\{\mathrm{A}-$ Surface $\}$ structure. From the deformation and adsorption energies calculated for one adsorbate, the energy of interaction $\mathrm{E}_{\text {int }}$ can be calculated according to Equation 3. The latter contains a contribution from the dispersion forces $\mathrm{E}_{\mathrm{int}, \mathrm{VdW}}$ and an electronic interaction $\mathrm{E}_{\text {int,elec }}$ that were calculated separately.

$$
\text { Equation } 3 \quad E_{\text {int }}=E_{\text {int,elec }}+E_{\text {int, }, \mathrm{dd}}=\Delta_{\text {ads }} E-E_{\text {def }}(\text { adsorbate })-E_{\text {def }}(\text { surface })
$$

The charge density obtained by these calculations was used to generate the charge density difference caused by the electronic adsorbate-surface interaction. 


\section{RESULTS AND DISCUSSION}

\section{Kinetic model}

180 The $\mathbf{C u} / \mathrm{SiO}_{2}$ material (Scheme 1a) is prepared via a surface organometallic chemistry approach $^{[25]}$ and consists of small copper nanoparticles $(1.2 \pm 0.6 \mathrm{~nm})$ dispersed on silica $(4.6 \mathrm{Cu}$ $\mathrm{wt} \% ; 130 \mu \mathrm{mol}_{\mathrm{H}_{2}} \cdot \mathrm{g}_{\mathrm{cat}}^{-1}$, ca. $290 \mu \mathrm{mol}_{\mathrm{Cu}_{\text {surface }}} \cdot \mathrm{g}_{\mathrm{cat}}^{-1}$, Figure S1) as previously reported, involving the grafting of $\mathrm{Cu}(\mathrm{I})$ mesityl on a silica partially dehydroxylated at $700{ }^{\circ} \mathrm{C}$ followed by a thermal treatment under a flow of $\mathrm{H}_{2}$ at $300{ }^{\circ} \mathrm{C} .{ }^{[17,}{ }^{18]}$ Kinetic alkyne hydrogenation studies were performed by monitoring the $\mathrm{H}_{2}$ uptake during the reaction while maintaining a constant pressure (quasi-isobaric conditions).

a)

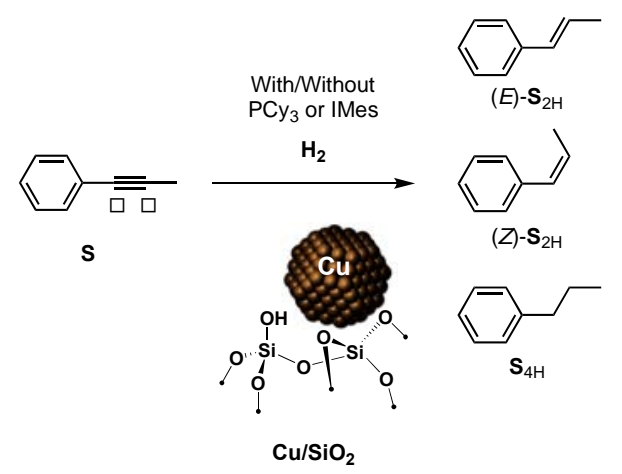

b)

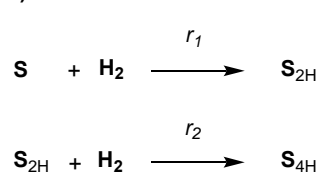

c)

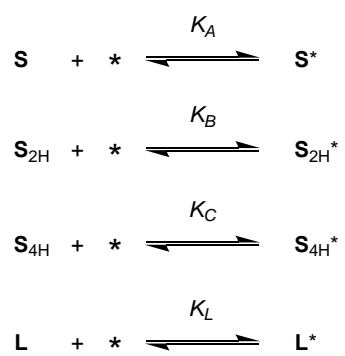

Scheme 1. a) Hydrogenation of 1-phenyl-1-propyne over $\mathbf{C u} / \mathrm{SiO}_{2}$ catalyst in the absence or in the presence of $\mathrm{PCy}_{3}$ or IMes ligand, b) hydrogenation steps and c) equilibria considered in this work.

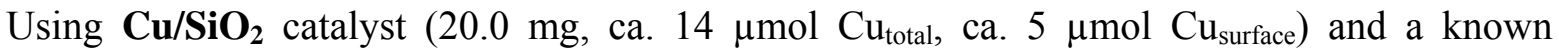
volume of toluene, the system is equilibrated at 10 bar $\mathrm{H}_{2}$ and $40{ }^{\circ} \mathrm{C}$ before a toluene solution of 1-phenyl-1-propyne $\left(1200 \mu \mathrm{mol}\right.$, Scheme 1a) preheated to $40^{\circ} \mathrm{C}$ is injected to the stirred 
suspension of $\mathbf{C u} / \mathbf{S i O}_{2}$. This procedure ensures that pressure changes occurring after introduction of $\mathbf{S}$ mostly result from the consumption of $\mathrm{H}_{2}$ by the hydrogenation reaction, minimizing the impact of factors such as temperature variations or liquid-gas phase reequilibration of $\mathrm{H}_{2}$ right after the injection. The $\mathrm{H}_{2}$ consumption profile is shown in Figure 1 (blue line).

a)

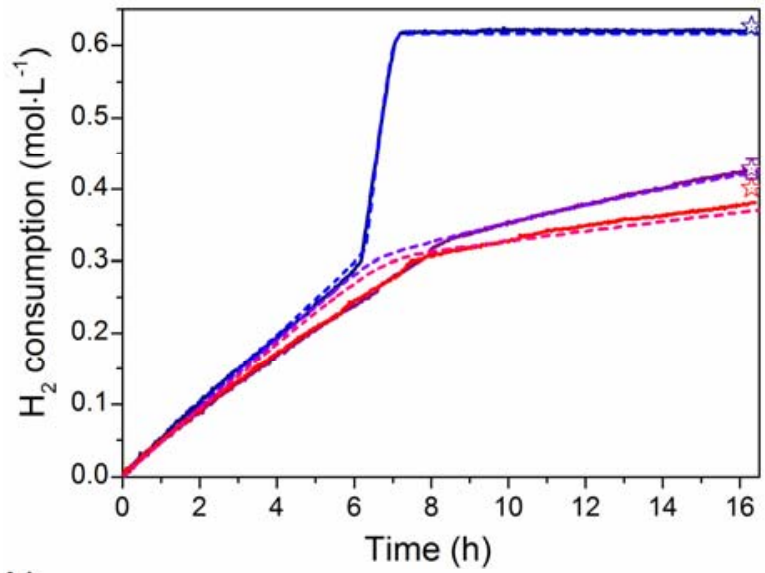

b)

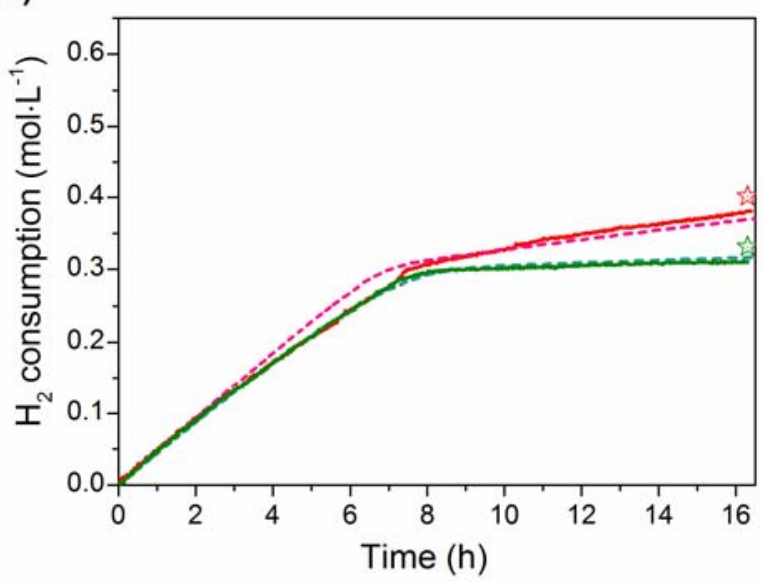

Figure 1. Experimental (solid lines) and fitted (dotted lines) $\mathrm{H}_{2}$ consumption profiles during hydrogenation of $\mathbf{S}$ with $\mathbf{C u} / \mathrm{SiO}_{2}$ (ca. $0.8 \mathrm{~mol} \% \mathrm{Cu}_{\text {total }}$ and $0.3 \mathrm{~mol} \% \mathrm{Cu}_{\text {surface }}$ vs $\mathbf{S}$ ) at 10 bar $\mathrm{H}_{2}$ and $40{ }^{\circ} \mathrm{C}$ with $\mathrm{H}_{2}$ consumption values at final time determined from $\mathrm{GC}$ conversions (stars), a) in the absence (blue) or in the presence of $\mathrm{PCy}_{3}$ in 1:50 (red) and 1:100 (purple) $\mathrm{PCy}_{3} / \mathrm{S}$ ratios and $b$ ) in the presence of $\mathrm{PCy}_{3}$ (red) or IMes (green) in $\mathbf{L} / \mathbf{S}$ 1:50 ratio. 
Two trends can be clearly identified. During the first ca. 6 hours of the reaction, $\mathrm{H}_{2}$ consumption follows a linear time dependence with a slope of $4.810^{-2} \mathrm{~mol}_{\mathrm{H}_{2}} \cdot \mathrm{L}^{-1} \cdot \mathrm{h}^{-1}$ followed by a sudden increase in the consumption rate (break) yielding a second linear regime with a faster rate of $3.710^{-1} \mathrm{~mol}_{\mathrm{H}_{2}} \cdot \mathrm{L}^{-1} \cdot \mathrm{h}^{-1}$. This second regime continues for ca. 1 hour before $\mathrm{H}_{2}$ consumption ends, which corresponds to the full overhydrogenation to 1-phenyl-1propane $\mathbf{S}_{4 \mathrm{H}}$ (Scheme 1a) as shown by GC analysis of the final mixture (Table S1). This observation is in agreement with results reported in our previous work for which full conversion to the alkane is observed at prolonged reaction times. ${ }^{[17]}$ The two observed linear regimes are consistent with two subsequent hydrogenation processes, which correspond to 1) the hydrogenation of $\mathbf{S}$ to 1-phenyl-1-propene $\mathbf{S}_{2 \mathrm{H}}$ (Scheme 1b), and 2) the subsequent hydrogenation of $\mathbf{S}_{2 \mathbf{H}}$ to $\mathbf{S}_{4 \mathrm{H}}$. For the first linear part of the trace (i.e. up to ca. 6 hours), we determined the dependence of $\mathrm{H}_{2}$ consumption rate taken as the slope of the first part of the curve on the substrate concentration, catalyst concentration and hydrogen pressure (partial orders, Equation S3, Figures S2-4 and Tables S2-4). We find first-order dependences of this rate on the catalyst concentration and on the hydrogen pressure, and a zero-order dependence on the substrate concentration, which is consistent with the linear trend observed.

Hydrogenation steps converting $\mathbf{S}$ to $\mathbf{S}_{2 \mathbf{H}}$ and $\mathbf{S}_{\mathbf{2}}$ to $\mathbf{S}_{\mathbf{4 H}}$ are described by the rates $r_{l}$ and $r_{2}$, respectively (Scheme 1b) and can be expressed according to a previously reported semiempirical model ${ }^{[26,27]}$ based on Langmuir-Hinshelwood formalism:

Equations 4 (a)

$$
r_{1}=k_{1, i n t} \frac{K_{H_{2}} P_{H_{2}}}{P^{0}} \frac{K_{A}[\boldsymbol{S}]}{\Gamma C^{0}}[*]_{t o t}=k_{1}^{a p p}[\boldsymbol{c a t}]\left(\frac{P_{H_{2}}}{P^{0}}\right) \frac{K_{A}[\boldsymbol{S}]}{\Gamma C^{0}}
$$

(b)

$$
r_{2}=k_{2, \text { int }} \frac{K_{\mathrm{H}_{2}} P_{\mathrm{H}_{2}}}{P^{0}} \frac{K_{B}\left[\boldsymbol{S}_{\mathbf{2 H}}\right]}{\Gamma C^{0}}[*]_{t o t}=k_{2}^{a p p}[\boldsymbol{c a t}]\left(\frac{P_{H_{2}}}{P^{0}}\right) \frac{K_{B}\left[\boldsymbol{S}_{\mathbf{2 H}}\right]}{\Gamma C^{0}}
$$

such that the rates of evolution of $\mathbf{S}\left(r_{A}\right), \mathbf{S}_{\mathbf{2}}\left(r_{B}\right)$ and $\mathbf{S}_{\mathbf{4 H}}\left(r_{C}\right)$ are expressed as in Equations 5a-c and the rate of consumption of $\mathrm{H}_{2}\left(r_{\mathrm{H}_{2}}\right)$ as monitored by the experimental setup is expressed as in

\section{Equation 5d:}

Equations 5 (a) $\quad r_{A}=-r_{1} \quad$ (b) $\quad r_{B}=r_{1}-r_{2} \quad$ (c) $\quad r_{C}=r_{2}$

$$
r_{H_{2}}=-r_{1}-r_{2}
$$


where $k_{i, \text { int }}$ are the intrinsic rate constants, $P_{H_{2}}$ is the pressure in hydrogen, $P^{0}$ the standard pressure $\left(P^{0}=1 \mathrm{bar}\right),[\boldsymbol{i}]$ the concentration of species $\boldsymbol{i}$ in solution, $[*]_{\text {tot }}$ the concentration of active sites, $C^{0}$ the standard concentration $\left(C^{0}=1 \mathrm{~mol} \cdot \mathrm{L}^{-1}\right)$. The respective adsorption constants $K_{i}$ of species $\boldsymbol{i}$ (substrates $\mathbf{S}, \mathbf{S}_{2 \mathbf{H}}$ and $\mathbf{S}_{4 \mathbf{H}}$ and ligand $\mathbf{L}$ ) on the active sites (Scheme 1c) are defined in Equations S4 ${ }^{[26,27]}$ and lead to the expression of the denominator $\Gamma$ containing inhibiting terms, given in Equation 6:

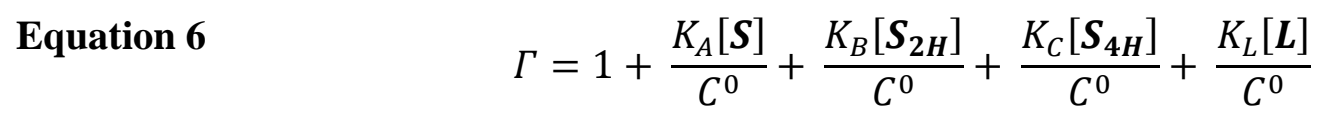

We note here that the exact nature of the active site, hence its exact concentration, is unknown. We assumed it proportional to the concentration of catalyst loaded in the reactor $\left([\boldsymbol{c a t}]\right.$, in $\left.\mathrm{g} \cdot \mathrm{L}^{-1}\right)$ : Equation 7

$$
[*]_{t o t}=\omega[\boldsymbol{c a t}]
$$

The adsorption constant $K_{\mathrm{H}_{2}}$ of $\mathrm{H}_{2}$ under catalytic conditions and the coefficient $\omega$ are not known and cannot be determined independently from the intrinsic rate constants. Thus, we do not attempt to deconvolve these terms from $k_{i, i n t}$ in the expressions of $r_{i}$ and restrict ourselves to the determination of apparent rate constants $k_{i}^{a p p}$ defined as in Equation 8:

Equation 8

$$
k_{i}^{a p p}=k_{i, i n t} K_{H_{2}} \omega
$$

The rate expressions ${ }^{[26,27]}$ (Equations 4 and 5) are all in first-order in the concentration of 235 catalyst $[\boldsymbol{c a t}]$ and in the $\mathrm{H}_{2}$ pressure $P_{\mathrm{H}_{2}}$. Thus, the rate of consumption of $\mathbf{S}\left(r_{A}\right.$, Equation 5a) follows indeed a first-order dependency with respect to the amount of catalyst and hydrogen pressure, which is in good agreement with our experimental observations (see above).

The rate $r_{A}$ of alkyne consumption has a complex order in [S] (Equations 4a and 5a) which degenerates into a zero-order dependence, as observed experimentally, provided that $K_{A}[\mathbf{S}]>>1$

$240+K_{B}\left[\mathbf{S}_{\mathbf{2 H}}\right]+K_{C}\left[\mathbf{S}_{\mathbf{4 H}}\right]$ (Equations 4a and 6). To assess this hypothesis and validate the model, we experimentally estimated values of adsorption constants $K_{i}$.

\section{Adsorption equilibria}


Adsorption isotherms of $\mathbf{S}, \mathbf{S}_{2 \mathrm{H}}$ and $\mathbf{S}_{4 \mathrm{H}}$ on $\mathbf{C u} / \mathbf{S i O}_{2}$ are recorded in toluene at $40{ }^{\circ} \mathrm{C}$ using a liquid pipetting robot operated inside a glovebox. Obtained adsorption data (Figure S5) is fitted using a Langmuir adsorption isotherm (Equation S6). Recording adsorption isotherms for both $(Z)$ and $(E)-\mathbf{S}_{2 \mathrm{H}}$ isomers revealed a substantial isomerization of the $(Z)$-isomer into the $(E)$ isomer. This isomerization makes interpretation of the isotherm of $(Z)-S_{2 H}$ ambiguous and we restrict ourselves to the analysis of $(E)-\mathbf{S}_{2 \mathbf{H}}$ isotherm for which little isomerization was observed.

Table 1. Adsorption constants obtained from the isotherms.

\begin{tabular}{cccc}
\hline Substrate & $\boldsymbol{K}$ & $\boldsymbol{K}$ value & $\begin{array}{c}\boldsymbol{Q} \\
\left(\mu \mathrm{mol}_{\text {substrate }} \cdot \mathrm{g}_{\text {cat }}{ }^{-1}\right)\end{array}$ \\
\hline $\mathbf{S}$ & $K_{A}$ & $8928 \pm 3301$ & $127 \pm 6$ \\
$(E)-\mathbf{S}_{\mathbf{2 H}}$ & $K_{B}$ & $554 \pm 75$ & $142 \pm 9$ \\
$\mathbf{S}_{\mathbf{4 H}}$ & $K_{C}$ & $352 \pm 59$ & $91 \pm 8$ \\
\hline
\end{tabular}

The resulting values for adsorption constants evolve in the order $K_{A} \gg K_{B}>K_{C}$ (Table 1, Equations S4), a trend that is in agreement with the literature data. ${ }^{[28,29]}$ Adsorption of substrates on the $\mathrm{SiO}_{2}$ support is negligible (data not shown), indicating that measured equilibrium constants evaluate the binding of respective adsorbates on copper nanoparticles. The very strong binding affinity of the alkyne for $\mathrm{Cu}$ does not allow obtaining relevant data points for the isotherm at low alkyne concentration. As a consequence, the reported $K_{A}$ value $\left(8.9 \cdot 10^{3}\right)$ is likely underestimated. While $K_{A}$ is at least one order of magnitude higher than $K_{B}$ and $K_{C}$, the latter constants are of the same order of magnitude, although it is expected that the propenyl moiety in $\mathbf{S}_{\mathbf{2 H}}$ would enhance the surface binding as compared to the propyl chain in $\mathbf{S}_{\mathbf{4 H}}$.

To better understand the origin of divergence between the experimental adsorption constants, we evaluated adsorption energies by DFT calculations (Table 2). We had previously reported that small $\mathrm{Cu}$ nanoparticles supported on silica mainly expose $\mathrm{Cu}(100)$ and $\mathrm{Cu}(111)$ terminations. ${ }^{[30]}$ Therefore, we have now calculated the adsorption of $\mathbf{S}, \mathbf{S}_{2 \mathbf{H}}$ and $\mathbf{S}_{4 \mathbf{H}}$ on $\mathrm{Cu}(100)$ and $\mathrm{Cu}(111)$ model surfaces to establish qualitative comparison of adsorptions affinities. For this comparison, we do not consider surface inhomogeneities (corners, edges,...), which are also part of the surface of CuNPs. 
Table 2. Components for adsorption energies computed on (100) and (111) $\mathrm{Cu} f c c$ surfaces. All energies are given in $\mathrm{kJ} \cdot \mathrm{mol}^{-1}$.

\begin{tabular}{|c|c|c|c|c|c|c|c|}
\hline Surface & Substrate & $\begin{array}{c}\mathrm{E}_{\mathrm{def}} \\
\text { (adsorbate) }\end{array}$ & $\begin{array}{c}\mathrm{E}_{\mathrm{def}} \\
\text { (surface) }\end{array}$ & $\mathrm{E}_{\text {int }}$ & $\mathrm{E}_{\text {int, } \mathrm{VdW}}$ & $E_{\text {int, elec }}$ & $\Delta_{\mathrm{ads}} \mathrm{E}^{\circ}$ \\
\hline \multirow{5}{*}{ (100) } & $\mathrm{S}$ & +228 & +18 & -450 & -159 & -291 & -204 \\
\hline & $(Z)-\mathbf{S}_{2 H}$ & +32 & +7 & -222 & -175 & -47 & -183 \\
\hline & $(E)-\mathbf{S}_{2 \mathbf{H}}$ & +44 & +8 & -241 & -174 & -67 & -189 \\
\hline & $\mathrm{S}_{4 \mathrm{H}}$ & +10 & -1 & -177 & -181 & +4 & -168 \\
\hline & Toluene & +11 & -1 & -149 & -143 & -6 & -139 \\
\hline \multirow{5}{*}{ (111) } & $S$ & +245 & +15 & -451 & -130 & -321 & -192 \\
\hline & $(Z)-\mathbf{S}_{2 \mathbf{H}}$ & +10 & +7 & -177 & -170 & -7 & -159 \\
\hline & $(E)-\mathbf{S}_{\mathbf{2 H}}$ & +15 & +11 & -186 & -169 & -17 & -161 \\
\hline & $\mathrm{S}_{4 \mathrm{H}}$ & +4 & +2 & -158 & -165 & +7 & -151 \\
\hline & Toluene & +3 & +2 & -125 & -128 & +3 & -120 \\
\hline
\end{tabular}

On both terminations, the most favorable adsorption mode of the alkyne $\mathbf{S}$ corresponds to the coordination of the alkyne moiety onto the $\mathrm{Cu}$ surface with a significant $\mathrm{sp}^{2}$-rehybridization of the $C_{\alpha}$ and $C_{\beta}$ (Scheme 1 and Figure 2a); these two carbons $\sigma$-bonded to the $\mathrm{Cu}$ surface atoms and the associated deformation impedes a large positive contribution to the adsorption energy $\left(+228 \mathrm{~kJ} \cdot \mathrm{mol}^{-1}\right.$ and $+245 \mathrm{~kJ} \cdot \mathrm{mol}^{-1}$ on $\mathrm{Cu}(100)$ and (111), respectively) (Table 2). However, this binding mode is associated with a significant modification of the charge density from the $\mathrm{C} \equiv \mathrm{C}$ 280 system towards $\mathrm{C}_{\alpha}$ and $\mathrm{C}_{\beta}-\mathrm{Cu}$ bonds (Figure 2a) and hence overall leads to strong binding $\left(\Delta_{\mathrm{ads}} \mathrm{E}=-204\right.$ and $-192 \mathrm{~kJ} \cdot \mathrm{mol}^{-1}$ on $\mathrm{Cu}(100)$ and $\mathrm{Cu}(111)$, respectively). These results are in agreement with a di- $\sigma / d i-\pi$ adsorbate of $\mathbf{S}$, as observed for alkynes on the $\mathrm{Cu}(111)$ surface ${ }^{[29,31}$, ${ }^{32]}$ and proposed for $\mathbf{S}^{[33]}$ On the (100) surface, the phenyl ring is almost parallel to the surface and plays a substantial role in surface-adsorbate interactions (Figure 2a). In contrast, the ring is tilted away from the surface on $\mathrm{Cu}(111)$ and does not influence the adsorption significantly. ${ }^{[33]}$ 
In the case of $\mathbf{S}_{2 \mathrm{H}}$, the adsorption mode does not lead to rehybridization, the phenyl ring retains its conjugation with the alkene moiety and $(Z)$ - and $(E)-\mathbf{S}_{2 \mathbf{H}} *$ adsorbates lay almost flat on both $\mathrm{Cu}(100)$ and $(111)^{[34]}$ surfaces (Figure $2 \mathbf{b}$ and S6). The alkenes are only marginally distorted upon adsorption, with much smaller deformation energies (between +10 and $+44 \mathrm{~kJ} \cdot \mathrm{mol}^{-1}$ ). 290 Adsorption energies are found at -183 and $-189 \mathrm{~kJ} \cdot \mathrm{mol}^{-1}$ on $\mathrm{Cu}(100)$, stronger than on $\mathrm{Cu}(111)$ $\left(-159\right.$ and $\left.-161 \mathrm{~kJ} \cdot \mathrm{mol}^{-1}\right)$, for $(Z)$ - and $(E)-\mathbf{S}_{2 \mathrm{H}} *$ respectively (Table 2$)$. Whereas the electronic interaction is the principal contribution in the stabilization of $\mathbf{S}^{*}$, Van der Waals (VdW) interactions are major components influencing the adsorption of $\mathbf{S}_{\mathbf{2 H}}$. However, these VdW interactions have very close contributions on both surfaces and do not explain the more favored 295 adsorption on $\mathrm{Cu}(100)$. This discrepancy is associated with the electronic interaction term (Table 2) which is found more stabilizing in the case of $\mathrm{Cu}(100)$ due to a specific overlap on the $\mathrm{Cu}(100)$ surface between the whole $\pi$ system of the molecule (phenyl ring and $-\mathrm{HC}=\mathrm{CH}-$ moiety) and the square arrangement of $\mathrm{Cu}$ atoms on this surface (Figure 2). This interaction also exists on $\mathrm{Cu}(111)$ although it is smaller in magnitude (Table 2). 
a)
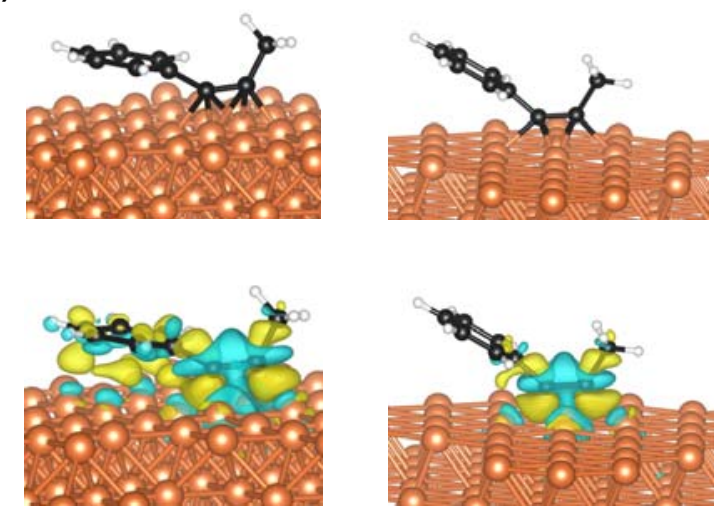

b)
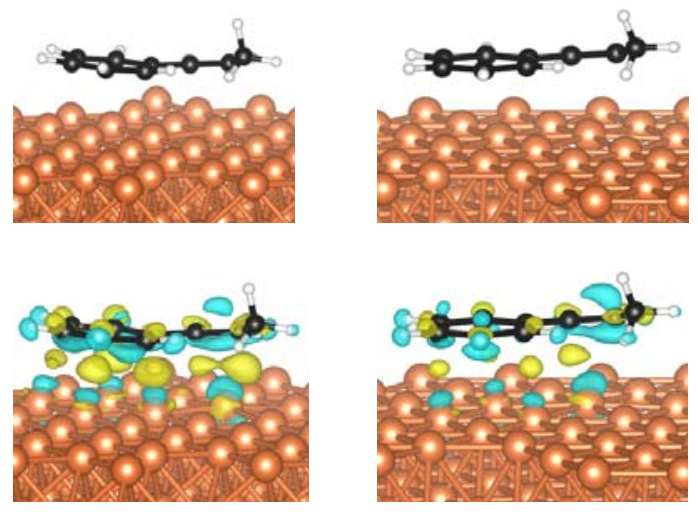

Figure 2. Molecular models for a) $\mathbf{S}$ and b) $(Z)-\mathbf{S}_{2 \mathbf{H}}$ adsorbed on the (100) and (111) terminations of $f c c$ copper. The bottom pictures show the charge density differences (see method section). Yellow and blue colors represent accumulation or depletion of charge density, respectively. The values for isosurfaces are $\pm 2.510^{-3} \mathrm{e} \cdot \AA^{-3}$ for all models.

Finally, $\mathbf{S}_{4 \mathbf{H}}$ mainly adsorbs via Van der Waals interactions (Table 2). The adsorption energies were found at -168 and $-151 \mathrm{~kJ} \cdot \mathrm{mol}^{-1}$ for $\mathrm{Cu}(100)$ and $(111)$, respectively. Note that $\mathbf{S}_{4 \mathbf{H}}{ }^{*}$ adsorbates are more stabilized than toluene (the solvent used in this study). This observation is in line with stronger $\mathrm{VdW}$ interactions for $\mathbf{S}_{\mathbf{4 H}} *$ than for toluene*, owing to the two additional methylene groups present in $\mathbf{S}_{\mathbf{4 H}}{ }^{[28,29]}$

Computed adsorption energies thus reproduce the trend observed experimentally for adsorption equilibrium $K$ constants $\left(K_{A}>>K_{B}>K_{C}\right)$. In particular, the significant affinity of $\mathbf{S}$ for Cu likely originates from its specific binding mode through coordination of the alkyne moiety to $\mathrm{Cu}$ sites. 
With $\mathrm{H}_{2}$ consumption curves and trends in $K$ values in hand, we now evaluate all relevant parameters $\left(k_{1}^{a p p}, k_{2}^{a p p}, K_{A}, K_{B}, K_{C}\right)$ describing our kinetic model against experimental results. Since $\mathrm{H}_{2}$ consumption traces do not allow differentiation of $\mathbf{S}_{2 \mathrm{H}}$ isomers, $K_{B}$ value reported below are apparent constants for sum of $(E)$ and $(Z)$ isomers, and the isomerization of $(Z)$ to $(E)$ 315 isomers is not modeled.

Fitting the experimental curves by setting $K_{A}, K_{B}, K_{C}$ to measured values from adsorption isotherms (vide supra) does not allow simulating the reaction profile adequately (Figure S7, RMSE $=3.610^{-2}$ ). In particular, the simulation fails to reproduce the very sharp break in slopes at ca. 6 hours observed in the experimental trace, pointing to the need of adjusting the adsorption constants values. On the other hand, fixing the single $K_{B}$ parameter to its measured value $\left(K_{B}=\right.$ 555 ) enables to fit the $\mathrm{H}_{2}$ consumption data fairly well (Figure 1a, blue lines, RMSE $=5.510^{-3}$ ); $k_{1}^{a p p}, k_{2}^{a p p}, K_{A}, K_{C}$ values are given in Table 3.

Table 3. Fitted parameters for the kinetic simulations shown in Figure 1. ${ }^{*} K_{B}$ was set to value found by adsorption isotherms.

\begin{tabular}{|c|c|}
\hline \multirow[t]{2}{*}{ Parameter } & Value \\
\hline & $k_{i}^{a p p}$ in $\mathrm{mol} \cdot \mathrm{g}_{\mathrm{cat}}{ }^{-1} \cdot \mathrm{h}^{-1}\left(\mathrm{~mol} \cdot \mathrm{kg}_{\mathrm{Cu}}{ }^{-1} \cdot \mathrm{h}^{-1}\right)$ \\
\hline$k_{1}^{a p p}$ & $9.810^{-4}\left(2.110^{1}\right)$ \\
\hline$k_{2}^{a p p}$ & $9.010^{-3}\left(2.010^{2}\right)$ \\
\hline$K_{A}$ & $7.410^{5}$ \\
\hline$K_{B}$ & $5.5510^{2 *}$ \\
\hline$K_{C}$ & $4.010^{1}$ \\
\hline$K_{L}\left(\mathrm{PC}_{3}\right)$ & $1.5510^{6}$ \\
\hline$K_{L}$ (IMes) & $3.7510^{6}$ \\
\hline
\end{tabular}


As expected from the difference in slopes between the hydrogenation of the alkyne and of the alkene, we find that $k_{2}^{a p p}$ is about one order of magnitude higher than $k_{1}^{a p p}$. This point shows that with $\mathbf{C u} / \mathrm{SiO}_{2}$ systems, the rate of the alkyne hydrogenation is slower than that of the alkene hydrogenation. This behavior is different from what is found for Pd- or Rh-based catalysts where the two hydrogenation rates are of the same order of magnitude. ${ }^{[35,36]}$ The fitted values of adsorption constant $K_{i}$ follow the same qualitative trend as the ones measured by adsorption experiments or obtained by DFT calculations, but differ quantitatively. We note that the relative $K_{i} / K_{j}$ ratios obtained from fitting do not depend on which adsorption constant is initially fixed to its experimental value in the fitting procedure. Specifically, $K_{A} / K_{B}$ and $K_{B} / K_{C}$ ratios shift from ca. $10^{1}$ and $10^{0}$ (isotherms) to $10^{3}$ and $10^{1}$ (fitting) respectively. This discrepancy could originate from two facts. First, as stated above, the $K_{A}$ value measured from adsorption isotherms is likely underestimated due the experimental limitations in the precise determination of the adsorbed quantities at low equilibrium concentrations. This point could partially explain the difference in $K_{A} / K_{B}$ ratios. Second, adsorption isotherm experiments and kinetic modelling do not probe the same surface adsorption sites (active vs. all adsorption sites), which would thus explain the difference in apparent $\mathrm{K}$ values. This point will be discussed further later.

It is possible to calculate the difference in free energy of adsorption at $40{ }^{\circ} \mathrm{C}$ $\left(\Delta\left(\triangle_{a d s} G^{\circ}\right)\left(40^{\circ} \mathrm{C}\right)\right)$ for the species using the relative values of $K$ determined from the kinetic modelling (Table 4). Although the contribution of the solvation to the free energy could not be assessed and we did not attempt to derive an absolute value for the adsorption constants from DFT calculations, the results are in qualitative agreement with the difference obtained from DFT calculations in adsorption energies on both (100) and (111) surfaces $\left(\Delta\left(\Delta_{a d s} E_{D F T}\right)\right)$. This point indicates that the (100) and (111) terminations are possible active sites for hydrogenation reactions.

Table 4. Adsorption energy constants from kinetic modelling and DFT calculations.

\begin{tabular}{ccccc}
\hline $\mathrm{i} / \mathrm{j}$ species & $K_{i} / K_{j}$ & $\begin{array}{c}\Delta\left(\Delta_{a d s} G^{\circ}\right)\left(40^{\circ} \mathrm{C}\right) \\
\left(\mathrm{kJ} \cdot \mathrm{mol}^{-1}\right)\end{array}$ & $\begin{array}{c}\Delta\left(\Delta_{a d s} E_{D F T}\right)(100) \\
\left(\mathrm{kJ} \cdot \mathrm{mol}^{-1}\right)\end{array}$ & $\begin{array}{c}\Delta\left(\Delta_{a d s} E_{D F T}\right)(111) \\
\left(\mathrm{kJ} \cdot \mathrm{mol}^{-1}\right)\end{array}$ \\
\hline $\mathbf{S} / \mathbf{S}_{\mathbf{2 H}}$ & $1.310^{3}$ & -18.7 & -21 & -33 \\
$\mathbf{S}_{\mathbf{2 H}} / \mathbf{S}_{\mathbf{4 H}}$ & $1.410^{1}$ & -6.8 & -15 & -8 \\
\hline
\end{tabular}


The kinetic modelling allows for simulating the evolution of concentrations of substrates in solution and surface adsorbates $\theta_{i}$ (Figure 3a,b and Equations S5) with time. The curves show that the active sites are exclusively occupied by the alkyne $\mathbf{S}^{*}$ as long as a significant proportion of $\mathbf{S}$ remains in solution (until about $6 \mathrm{~h}$ ). The large difference between $K_{A}$ and $K_{B}$ prevents $\mathbf{S}_{2 \mathbf{H}}$ formed during this period from re-adsorbing and further reacting to form $\mathbf{S}_{\mathbf{4 H}}$. Once $\mathbf{S}$ is depleted in solution, $\mathbf{S}_{2 \mathrm{H}}$ can adsorb and quickly react to form $\mathbf{S}_{\mathbf{4 H}}$ quantitatively within $1 \mathrm{~h}$. $\mathbf{S}_{4 \mathrm{H}}$ itself is not able to displace the adsorbed $\mathbf{S}_{2 \mathrm{H}}$ and its coverage on the surface remains low until $\mathbf{S}_{2 \mathbf{H}}$ is depleted. Thus, $\mathbf{S}_{4 \mathbf{H}}$ does not significantly inhibit the overhydrogenation reaction. These results are consistent with the kinetic traces as assessed from the reported GC conversion data, ${ }^{[17]}$ for which the evolution in concentrations during hydrogenation could be adequately fitted for all species $\left(\mathbf{S}, \mathbf{S}_{\mathbf{2 H}}, \mathbf{S}_{\mathbf{4 H}}\right)$ using the same model and constants (Figure S9 and Table $\mathbf{3}$ ).

a)

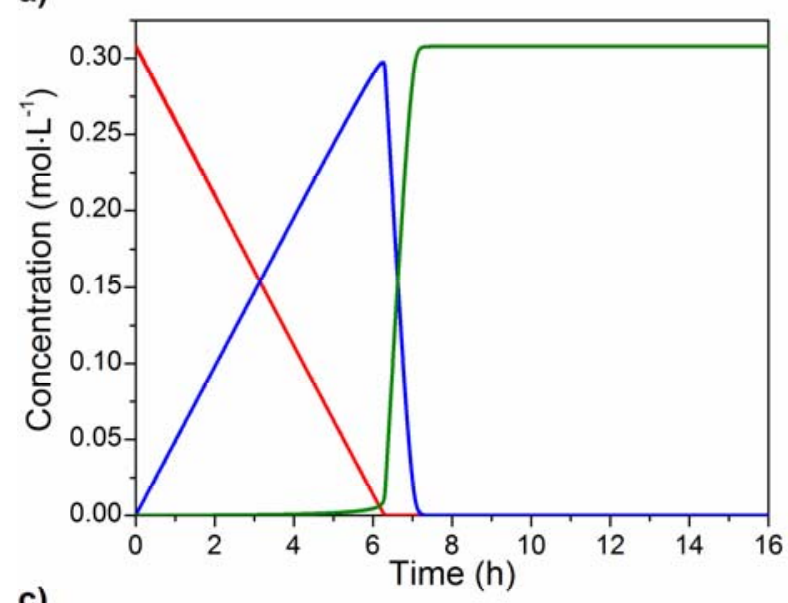

c)

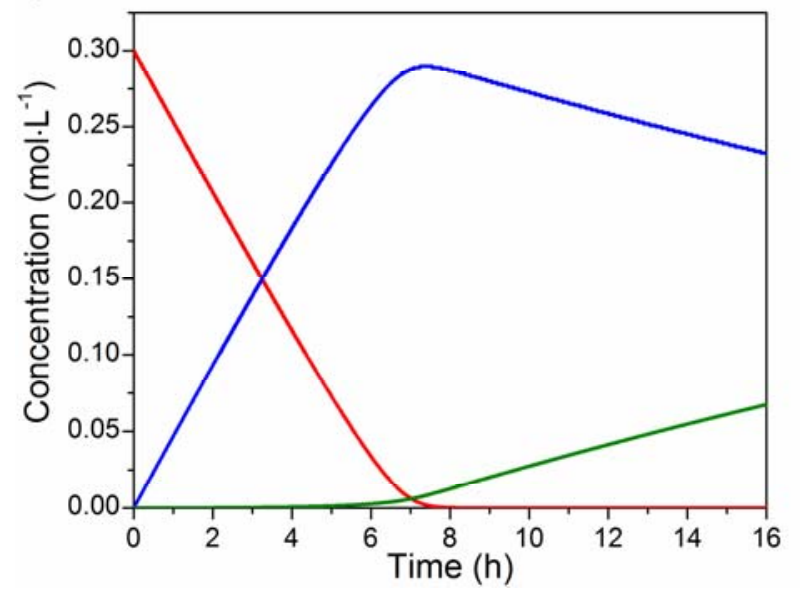

b)

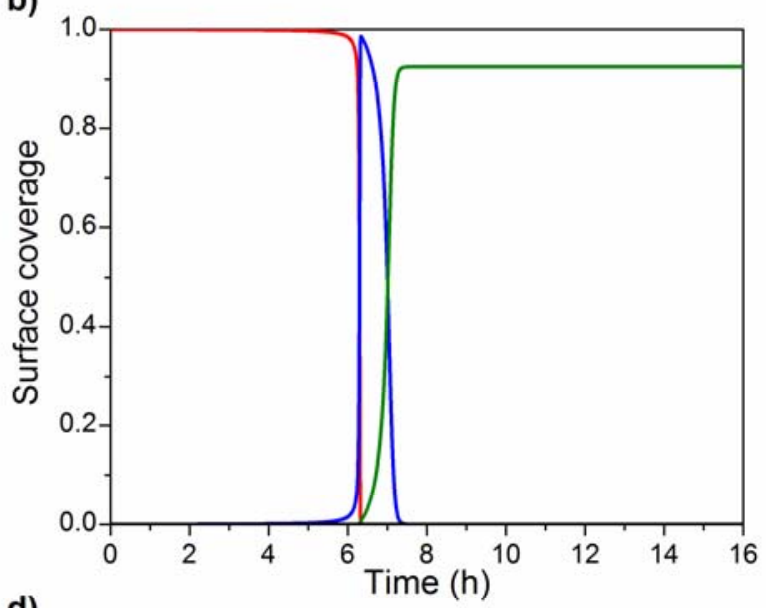

d)

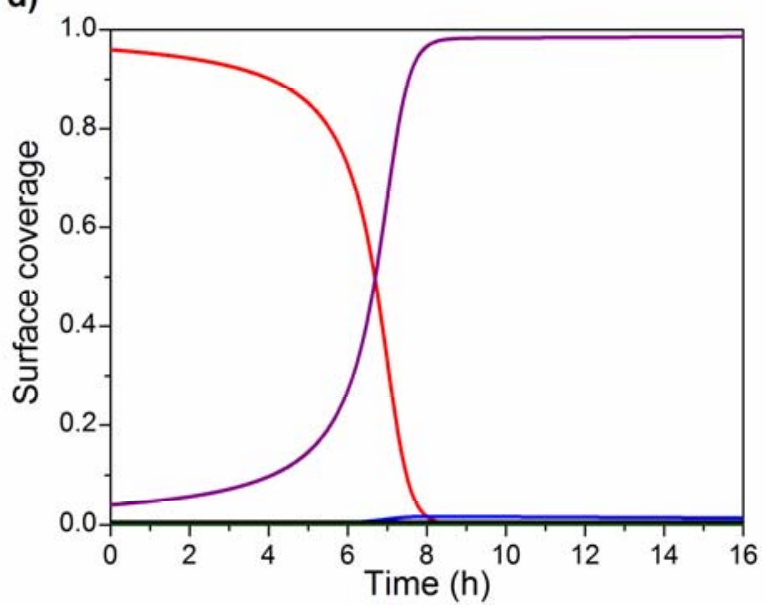


Figure 3. a,c) Simulated concentrations in $\mathbf{S}$ (red), $\mathbf{S}_{2 \mathbf{H}}$ (blue), $\mathbf{S}_{4 \mathbf{H}}$ (green) and b,d) surface coverage on $\mathbf{C u} / \mathbf{S i O}_{2}$ in $\mathbf{S}^{*}$ (red), $\mathbf{S}_{2} \mathbf{H}^{*}$ (blue), $\mathbf{S}_{4 \mathbf{H}} *$ (green), $\mathrm{PCy}_{3} *$ (purple) and empty sites * (black) a,b) in the absence or c,d) in the presence of $\mathrm{PCy}_{3}$ in a 1:50 $\mathrm{PCy}_{3} / \mathbf{S}$ ratio.

\section{Influence of ligands}

Overall, overhydrogenation from $\mathbf{S}_{2 \mathrm{H}}$ to $\mathbf{S}_{4 \mathrm{H}}$ occurs at a fast rate on $\mathbf{C u} / \mathrm{SiO}_{2}$ once $\mathbf{S}$ is fully consumed. However, overhydrogenation at full alkyne conversion can be efficiently shut down by introducing an additive (ligand) to the reaction mixture. ${ }^{[17]}$ Specifically, $\mathrm{PCy}_{3}$ limits overhydrogenation of several alkyne substrates, including 1-phenyl-1-propyne, for which $94 \%$ selectivity for $(Z)-S_{2 \mathrm{H}}$ was observed shortly after the full conversion of $\mathbf{S}\left(40{ }^{\circ} \mathrm{C}, 20\right.$ bar $\left.\mathrm{H}_{2}\right)$. These results thus put into question the origin of the increase of selectivity upon addition of a ligand such as $\mathrm{PCy}_{3}$. The role of surface co-adsorbates in alkyne hydrogenation has been reported on different catalytic nanoparticulate systems. ${ }^{[37-39]}$ We postulate that similar effects could determine the selectivity in our $\mathbf{C u} / \mathrm{SiO}_{2}$ system. The adsorption of an additive acting as an inhibitor ligand $(\mathbf{L})$ to $\mathrm{Cu}$ nanoparticles and described by its adsorption equilibrium constant $K_{L}$ can be formalized within the Langmuir-Hinshelwood model by an additional $K_{L}[\mathrm{~L}]$ term in the expression of $\Gamma$ (Equation 6).

380 To verify this hypothesis, the hydrogenation of $\mathbf{S}$ is carried out in the presence of $\mathrm{PCy}_{3}$ under otherwise identical conditions. We use two different $\mathrm{PCy}_{3} / \mathbf{S}$ molar ratio (1:50 and 1:100) and record $\mathrm{H}_{2}$ consumption traces (Figure 1a). Two trends can be identified in the traces. From initial time to ca $6 \mathrm{~h}, \mathrm{H}_{2}$ consumption displays a quasi-linear behavior with a slope slightly lower than the one observed in the absence of the ligand. The second part of the trace is also linear, but in this case the slope is significantly flatter than for the first part and it decreases with increasing the $\mathrm{PCy}_{3} / \mathbf{S}$ molar ratio. These features can indicate that hydrogenation from $\mathbf{S}$ to $\mathbf{S}_{2 \mathbf{H}}$ occurs at similar rates both with or without added ligand but overhydrogenation of $\mathbf{S}_{\mathbf{2 H}}$ to $\mathbf{S}_{4 \mathbf{H}}$ is hindered by $\mathrm{PCy}_{3}$. GC analysis of the reaction mixture after 16 hours confirms that $\mathrm{PCy}_{3}$ slows down overhydrogenation since in its presence selectivity to $\mathbf{S}_{4 \mathbf{H}}$ is only $36 \%\left(\mathrm{PCy}_{3} / \mathbf{S}=1: 50\right)$ or $41 \%\left(\mathrm{PCy}_{3} / \mathbf{S}=1: 100\right)$ compared to $>99 \%$ in its absence (Table S1).

Fitting simultaneously the experimental traces for both $\mathrm{PCy}_{3} / \mathrm{S}$ ratios using the set of constants calculated previously without ligand in solution and optimizing only the adsorption constant of the ligand $K_{L}$ (Equation S4d) successfully reproduced the experimental traces with a value of $K_{L}$ 
of $1.5510^{6}$ (Figure 1a, RMSE $=1.210^{-2}$ and $1.810^{-2}$ for $\mathrm{PCy}_{3} / \mathrm{S}=1: 50$ and 1:100, respectively). This value is in line with the strongly favored adsorption of $\mathrm{PCy}_{3}$ on $\mathrm{Cu} \mathrm{NPs}$. Because of this strong adsorption, we did not attempt to measure the adsorption isotherms for $\mathrm{PCy}_{3}$, as it would fall outside the sensitivity limits of our setup.

Figure 3c,d shows that the ligand competes with $\mathbf{S}$ for the adsorption on the active sites. Surface coverage in $\mathbf{L}^{*}$ is initially $4 \%$, whereas $\mathbf{S}^{*}$ is still the major surface species. Due to the relative $K_{i} C_{i}$ products $\mathbf{L}^{*}$ becomes the major adsorbate only once $\mathbf{S}$ gets significantly depleted. In contrast, $\mathbf{S}_{\mathbf{2 H}}$ is not able to displace $\mathbf{L}^{*}$ from the active sites, and only a small fraction of $\mathbf{S}_{\mathbf{2}}$ * exists on the surface (below $2 \%$ ) during the second kinetic regime. This low coverage in $\mathbf{S}_{2 \mathbf{H}}$ explains the observed slow overhydrogenation rate.

Overall, all experimental traces are adequately modelled using the same set of constants, a point that validates the approach used here and the use of a Langmuir-Hinshelwood model. This finding can be extended to other ligands, for instance an N-heterocyclic carbene IMes $(1,3-$ bis(2,4,6-trimethylphenyl)imidazol-2-ylidene), which also leads to improved selectivity. ${ }^{[17]}$ Hydrogenation of $\mathbf{S}$ with IMes/S 1:50 ratio (Figure 1b) gave traces of similar shape than observed with $\mathrm{PCy}_{3} / \mathrm{S}$ 1:50. In that case however, the second part of the curve displays a quasi410 flat linear slope, pointing to a very low overhydrogenation rate. Accordingly, the GC analysis after 16 hours reveals only 10\% of overhydrogenation (Table S1). Modelling the experimental trace with the Langmuir-Hinshelwood formalism results in a satisfactory fit (Figure 1b, RMSE $=3.410^{-3}$ ). $K_{L}$ value for IMes is fitted at $3.7510^{6}$, ca. twice higher than for $\mathrm{PCy}_{3}$. This higher value is in line with the improved electron-donating abilities of the IMes $\mathrm{NHC}^{[40,41]}$ that makes it a particularly strong ligand.

Note that, under our conditions, no significant $k_{1}^{a p p}$ enhancement is observed due to the presence of ligands. However, we cannot rule out that ligand can impact alkyne hydrogenation rates to a minor extent, which might depend on $\mathbf{L} / \mathbf{S}$ ratios.

Overall, our observations demonstrate that introducing a ligand with an appropriate adsorption 420 constant $K$ value $\left(K_{L} \approx K_{A} \gg K_{B}\right)$ is a powerful strategy to strongly hinder overhydrogenation and reach selectivity for alkene higher than $90 \%$ even at prolonged reaction times using $\mathbf{C u} / \mathbf{S i O}_{2}$ system.

\section{Discussion}


The simple Langmuir-Hinshelwood formalism used here enables modelling the experimental results appropriately and sheds light on the main features of alkyne hydrogenation with $\mathrm{Cu} / \mathrm{SiO}_{2}$ systems:

- the apparent rate of hydrogenation of the alkene to the alkane is faster than that of hydrogenation of the alkyne to the alkene, and thus $\mathbf{C u} / \mathbf{S i O}_{2}$ has no intrinsic selectivity towards semihydrogenation at full conversion of the alkyne;

- the selectivity is mainly driven by the competitive substrate adsorption on the $\mathrm{Cu}$ nanoparticles;

- the adsorption constant of the alkyne on $\mathbf{C u} / \mathbf{S i O}_{2}$ is orders of magnitude higher than that of the alkene, yielding displacement of the alkene by the alkyne up to relatively high conversion of the alkyne;

- the addition of a ligand allows the selective displacement of the alkene from the $\mathrm{Cu}$ active sites and thus hinders the overhydrogenation process, including at full conversion of the alkyne.

Our results show that very different adsorption constants of the alkyne and the alkene on the $440 \mathrm{Cu}$ surface make two hydrogenation processes at $40^{\circ} \mathrm{C}$ occur in two distinct and successive regimes with minimal overlap. In this context, the appropriate choice of a ligand that binds stronger than the alkene but not than the alkyne permits shutting down the overhydrogenation of the alkene while maintaining similar alkyne hydrogenation rates as observed without added ligand. Thus, high semihydrogenation selectivity requires the adsorption constants and concentrations of the species to follow the relationship:

$$
K_{A}[\mathbf{S}]>K_{L}[\mathbf{L}]>>K_{B}\left[\mathbf{S}_{2 \mathbf{H}}\right]
$$

While substrate-dependent, this strategy remains an attractive and simple option for alkynes that exhibit sufficiently different adsorption constants than the respective alkenes so that an appropriate ligand satisfying the above condition can be found. Hydrogenation of 1-phenyl-1hexyne (Figure S10) that is structurally close to 1-phenyl-1-propyne proceeds in a similar stepwise fashion over the pristine $\mathbf{C u} / \mathbf{S i O}_{2}$ catalyst; the overhydrogenation step can likewise be hindered upon introduction of $\mathrm{PCy}_{3}$ in 1:50 L/alkyne ratio (Figure S10). This point suggests that the ligand-driven selectivity in Cu-based semihydrogenation expands to internal alkyl alkynes bearing aromatic groups. In addition, the strong adsorption of the alkyne $\mathbf{S}$ is mainly driven through the interaction of the $\mathrm{C} \equiv \mathrm{C}$ bond with the $\mathrm{Cu}$ surface. Since this interaction relates to the 
chemical nature of the triple bond itself and not the substituents, it can also explain the good chemoselectivity observed previously for dialkyl alkynes. Although an extended ligand/substrate screening is out of the scope of this work, ${ }^{13}$ we note that the selection of an appropriate ligand for a particular alkyne could be aided by measuring and/or calculating respective adsorption isotherms, as described above. Such strategy based on a ligand-driven selectivity is reminiscent to the earlier proposal of using $\mathrm{CO}$ or other co-adsorbate for the gas-phase semihydrogenation of alkynes on Pd or Au surface. ${ }^{[42-44]}$

However, the values of adsorption constants $K_{i}$ derived from the adsorption isotherms differ significantly from $K_{i}$ values determined by modelling the kinetic data, even though both approaches agree qualitatively. This difference may indicate that each method probes different adsorption sites. While adsorption isotherms likely involve all possible adsorption sites, kinetics is specifically sensitive to the catalytically active sites. This discrepancy in $K_{i}$ values therefore suggests that active hydrogenation sites are probably only a fraction of all possible adsorption sites. Thus, two different types of sites with different reactivity are probably involved in this system, as already observed on Pd-based alkyne semihydrogenation catalysts. ${ }^{[45,46]}$ In catalysis by metal nanoparticles, a number of reports show that different domains of nanoparticles, e.g. terraces and edges or corners, can have different reactivities ${ }^{[47-49]}$ and we note that the relative surface densities of different sites might vary depending on the preparation method. In line with this point, Tysoe et al. have previously shown that the adsorption of terminal alkenes is significantly stronger on $\mathrm{Cu}$ foil than on $\mathrm{Cu}$ single-crystal (111) terminations while the adsorption of corresponding terminal alkynes does not differ quite as much on both surfaces. ${ }^{[29]}$ These results indicate that inhomogeneities (corners, edges, ...) may have different reactivity than terraces. While 2-site model also provides adequate fits (not shown), it was not possible to discriminate here which model (1-site or 2-site) is more relevant. Since the one-site model involves twice less parameters than the 2-site model, we found it more suitable at this stage.

Another important observation is that the $k_{2}^{a p p}$ rate constant for alkene overhydrogenation is almost one order of magnitude higher than that for alkyne semihydrogenation $\left(k_{1}^{a p p}\right)$. Such a trend is usually not observed on classical systems for alkyne semihydrogenation (such as Pdbased catalysts), for which alkene conversion is slower or of the same order as alkyne conversion. $^{[35,36,50]}$ This behavior seems to be specific to copper, and might be related to its intrinsic reactivity with alkynes and alkenes (through the $k_{i, \text { int }}$ ), but could also originate from 
different availability of hydrogen at the surface depending on the presence of adsorbates. Copper is indeed known to bind hydrogen much weaker than other metals (Pd for instance) ${ }^{[51]}$ and the very specific and strong binding mode of the alkyne obtained by DFT may further disfavor the chemisorption of hydrogen. However, our current experimental data does not allow discriminating $k_{i, \text { int }}$ from $K_{H 2}$ to settle this point.

Overall, although very simple, the reactivity model presented above provides general rules and guidelines on how to tune the selectivity towards semihydrogenation for $\mathbf{C u} / \mathrm{SiO}_{2}$ catalysts.

\section{CONCLUSION}

The $\mathrm{H}_{2}$ consumption traces in the hydrogenation of a prototypical alkyne substrate (1-phenyl1-propyne) on $\mathbf{C u} / \mathrm{SiO}_{2}$ can be successfully modelled using a Langmuir-Hinshelwood formalism. The hydrogenation of 1-phenyl-1-propyne is a two-step process. First, the alkyne is hydrogenated into the alkene, which is subsequently hydrogenated into the alkane. Although the hydrogenation rate for the alkene is faster than for the alkyne, a clear bi-linear behavior is observed owing to the highly favored adsorption of the alkyne onto the $\mathrm{Cu}$ surface. DFT calculations show that rehybridization occurs at the sp carbon atoms upon adsorption of the alkyne on either $\mathrm{Cu}(100)$ or (111) surfaces to yield a di- $\sigma / d i-\pi$ adsorbate. This specific interaction strongly stabilizes the alkyne adsorbate, which explains its preferred binding compared to the alkene and the alkane.

Whereas at present it is not possible to discriminate if both hydrogenation steps occur on the same active site, the simple model used here provides an overall satisfactory modelling of the experimental data. We also noted that the alkene is hydrogenated faster than the alkyne, a phenomenon that possibly arises from different active sites or different availability of hydrogen on the surface depending on the substrate. This point is currently under investigation.

In the presence of a ligand ( $\mathrm{PCy}_{3}$ or IMes) in the catalytic mixture, the rate of hydrogenation of 515 the alkyne is barely affected, but overhydrogenation to the alkane is greatly hindered. We have shown that this behavior is due to the competitive adsorption of the ligand and the substrates on a 
$\mathrm{Cu}$ NP surface. Specifically, adsorption constants of ligands are found to be of the same order of magnitude as for the alkyne, but much higher than for olefin products. Displacing the alkene from the surface, the ligand favors semihydrogenation vs. overhydrogenation. Remarkably, with the strongly donating IMes ligand the rate of overhydrogenation is very low and selectivity for the alkene remains at $90 \%$ at full conversion, even after $16 \mathrm{~h}$.

Our findings show that the use of ligands with appropriate adsorption constants can lead to high selectivity for alkyne semihydrogenation on $\mathbf{C u} / \mathbf{S i O}_{2}$, which is inherently non-selective in the absence of ligands. This study provides a guideline to improve the selectivity of a cheap, earth-abundant $\mathrm{Cu}$ catalyst and to ultimately replace the classical, expensive and toxic Lindlar catalyst for alkyne semihydrogenation.

\section{ASSOCIATED CONTENT}

530 Supporting Information. $\mathrm{H}_{2}, \mathrm{CO}$ and substrate adsorption isotherms, partial orders determination, kinetic traces, GC data, DFT geometries. The following files are available free of charge.

\section{AUTHOR INFORMATION}

\section{Corresponding Author}

* ccoperet@inorg.chem.ethz.ch

\section{Author Contributions}

†These authors contributed equally.

\section{Funding Sources}

540 We are grateful to the Scientific Equipment Program of ETH Zürich and the SNSF (R'Equip grant 206021_150709/1) for financial support of the high throughput catalyst screening facility (HTE@ETH). N.K. acknowledges support from the ETH Zürich Postdoctoral Fellowship Program and from the Marie Curie Actions for People COFUND Program. K.L. thanks support 
of the ETH Carreer Seed Grant SEED-21 16-2. A.F. thanks the Holcim Stiftung for a habilitation

fellowship. The development of supported $\mathrm{Cu}$ catalysts was also partially funded by the SCCER

Heat and Energy Storage.

\section{REFERENCES}

[1] C. Oger, L. Balas, T. Durand, J.M. Galano, Chem. Rev., 113 (2013) 1313.

[2] G. Vilé, D. Albani, N. Almora-Barrios, N. López, J. Pérez-Ramírez, ChemCatChem, 8 (2016) 55021.

[3] H. Lindlar, Helv. Chim. Acta, 35 (1952) 446.

[4] M. Crespo-Quesada, F. Cárdenas-Lizana, A.-L. Dessimoz, L. Kiwi-Minsker, ACS Cat., 2 (2012) 1773.

[5] F. Studt, F. Abild-Pedersen, T. Bligaard, R.Z. Sorensen, C.H. Christensen, J.K. Norskov, 555 Science, $320(2008) 1320$.

[6] F. Chen, C. Kreyenschulte, J. Radnik, H. Lund, A.-E. Surkus, K. Junge, M. Beller, ACS Cat., 7 (2017) 1526.

[7] C. Chen, Y. Huang, Z. Zhang, X.Q. Dong, X. Zhang, Chem. Commun., 53 (2017) 4612.

[8] P.T. Witte, P.H. Berben, S. Boland, E.H. Boymans, D. Vogt, J.W. Geus, J.G. Donkervoort,

560 Top. Catal., 55 (2012) 505.

[9] S.A. Nikolaev, L.N. Zanaveskin, V.V. Smirnov, V.A. Averyanov, K.L. Zanaveskin, Russ. Chem. Rev., 78 (2009) 231.

[10] A.M. Whittaker, G. Lalic, Org. Lett., 15 (2013) 1112.

[11] G.-H. Wang, H.-Y. Bin, M. Sun, S.-W. Chen, J.-H. Liu, C.-M. Zhong, Tetrahedron, 70 565 (2014) 2175.

[12] N.O. Thiel, S. Kemper, J.F. Teichert, Tetrahedron, 73 (2017) 5023.

[13] T. Wakamatsu, K. Nagao, H. Ohmiya, M. Sawamura, Organometallics, 35 (2016) 1354.

[14] Y. Nakao, K. Semba, R. Kameyama, Synlett, 26 (2015) 318.

[15] H. Kominami, M. Higa, T. Nojima, T. Ito, K. Nakanishi, K. Hashimoto, K. Imamura, $570 \quad$ ChemCatChem, 8 (2016) 2019.

[16] J.T. Wehrli, D.J. Thomas, M.S. Wainwright, D.L. Trimm, N.W. Cant, Appl. Catal., 70 (1991) 253.

[17] A. Fedorov, H.J. Liu, H.K. Lo, C. Coperet, J. Am. Chem. Soc., 138 (2016) 16502.

[18] O.G. Salnikov, H.J. Liu, A. Fedorov, D.B. Burueva, K.V. Kovtunov, C. Coperet, I.V.

575 Koptyug, Chem. Sci., 8 (2017) 2426.

[19] L. Jafarpour, E.D. Stevens, S.P. Nolan, J. Organomet. Chem., 606 (2000) 49.

[20] R.J. Hue, I.A. Tonks, J. Vis. Exp., (2015) e53212.

[21] G. Kresse, J. Furthmüller, Phys. Rev. B, 54 (1996) 11169.

[22] G. Kresse, J. Hafner, Phys. Rev. B, 49 (1994) 14251.

580 [23] J.P. Perdew, K. Burke, M. Ernzerhof, Phys. Rev. Lett., 77 (1996) 3865.

[24] S. Grimme, J. Antony, S. Ehrlich, H. Krieg, J. Chem. Phys., 132 (2010) 154104.

[25] C. Coperet, A. Comas-Vives, M.P. Conley, D.P. Estes, A. Fedorov, V. Mougel, H. Nagae,

F. Nunez-Zarur, P.A. Zhizhko, Chem. Rev., 116 (2016) 323.

[26] L. Červený, V. Růžička, Cat. Rev., 24 (1982) 503.

585 [27] L. Červenýa, V. Rûržička, Adv. Catal., 30 (1981) 335. 
[28] A.V. Teplyakov, A.B. Gurevich, M.X. Yang, B.E. Bent, J.G. Chen, Surf. Sci., 396 (1998) 340.

[29] B.P. Miller, O.J. Furlong, W.T. Tysoe, Surf. Sci., 616 (2013) 143.

[30] K. Larmier, S. Tada, A. Comas-Vives, C. Coperet, J. Phys. Chem. Lett., 7 (2016) 3259.

590 [31] A. Valcarcel, J.M. Ricart, A. Clotet, A. Markovits, C. Minot, F. Illas, J. Chem. Phys., 116 (2002) 1165.

[32] R.L. Toomes, R. Lindsay, P. Baumgärtel, R. Terborg, J.T. Hoeft, A. Koebbel, O. Schaff, M. Polcik, J. Robinson, D.P. Woodruff, A.M. Bradshaw, R.M. Lambert, J. Chem. Phys., 112 (2000) 7591.

595 [33] Y. Sohn, W. Wei, J.M. White, Langmuir, 23 (2007) 12185.

[34] C. Kolczewski, F.J. Williams, R.L. Cropley, O.P. Vaughan, A.J. Urquhart, M.S. Tikhov, R.M. Lambert, K. Hermann, J. Chem. Phys., 125 (2006) 34701.

[35] T.A. Nijhuis, G. van Koten, F. Kapteijn, J.A. Moulijn, Catal. Today, 79-80 (2003) 315.

[36] T.A. Nijhuis, G. van Koten, J.A. Moulijn, Appl. Catal., A, 238 (2003) 259.

600 [37] J.L. Fiorio, N. López, L.M. Rossi, ACS Cat., 7 (2017) 2973.

[38] S.G. Kwon, G. Krylova, A. Sumer, M.M. Schwartz, E.E. Bunel, C.L. Marshall, S.

Chattopadhyay, B. Lee, J. Jellinek, E.V. Shevchenko, Nano Lett., 12 (2012) 5382.

[39] J.A. Delgado, O. Benkirane, C. Claver, D. Curulla-Ferre, C. Godard, Dalton Trans., 46 (2017) 12381.

605 [40] M.N. Hopkinson, C. Richter, M. Schedler, F. Glorius, Nature, 510 (2014) 485.

[41] T. Droge, F. Glorius, Angew. Chem. Int. Ed., 49 (2010) 6940.

[42] N. López, B. Bridier, J. Pérez-Ramírez, J. Phys. Chem. C, 112 (2008) 9346.

[43] A.J. McCue, F.-M. McKenna, J.A. Anderson, Cat. Sci. Techno., 5 (2015) 2449.

[44] B. Bridier, M.A.G. Hevia, N. López, J. Pérez-Ramírez, J. Catal., 278 (2011) 167.

610 [45] G.C. Bond, Hydrogenation of Alkynes, Springer US, Boston, MA, 2005.

[46] A. Borodziński, G.C. Bond, Cat. Rev., 50 (2008) 379.

[47] M. Behrens, F. Studt, I. Kasatkin, S. Kuhl, M. Havecker, F. Abild-Pedersen, S. Zander, F. Girgsdies, P. Kurr, B.L. Kniep, M. Tovar, R.W. Fischer, J.K. Norskov, R. Schlogl, Science, 336 (2012) 893.

615 [48] M.P. Andersson, F. Abild-Pedersen, I.N. Remediakis, T. Bligaard, G. Jones, J. Engbæk, O. Lytken, S. Horch, J.H. Nielsen, J. Sehested, J. Catal., 255 (2008) 6.

[49] R.T. Vang, K. Honkala, S. Dahl, E.K. Vestergaard, J. Schnadt, E. Lægsgaard, B.S. Clausen,

J.K. Nørskov, F. Besenbacher, Surf. Sci., 600 (2006) 66.

[50] F.-M. McKenna, J.A. Anderson, J. Catal., 281 (2011) 231.

620 [51] G.C. Bond, Chemisorption and Reactions of Hydrogen, Springer US, Boston, MA, 2005. 
GRAPHICAL ABSTRACT

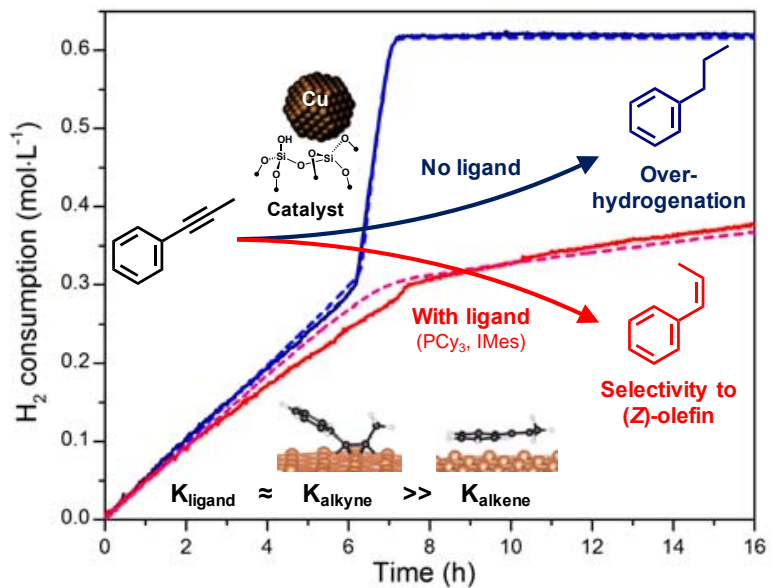

625 